\title{
Hepatic retractor in an ex vivo model $^{1}$
}

Delano Gurgel Silveira', Márcio Alencar Barreira", Luiz Gonzaga de Moura Junior"I', Charles Jean Gomes de Mesquita"', Hermano Alexandre Lima Rochaiv, Gleydson Cesar de Oliveira Borges`

'Fellow Master degree, Postgraduate Program in Minimally Invasive Technology and Health Simulation, Centro Universitário Christus (UNICHRISTUS), Fortaleza-CE, Brazil. Conception and design of the study; technical procedures; acquisition, interpretation and analysis of data; manuscript preparation and writing.

"MD, General Surgeon, Hospital Universitário Walter Cantídio, Fortaleza-CE, Brazil. Manuscript preparation, critical revision.

I'PhD, Assistant Professor, Professional Master's Degree Program in Minimally Invasive Technology and Simulation in Health, UNICHRISTUS, Fortaleza-CE, Brazil. Conception and design of the study, critical revision.

IVPhD, Assistant Professor, Professional Master's Degree Program in Minimally Invasive Technology and Simulation in Health, UNICHRISTUS, Fortaleza-CE, Brazil. Conception and design of the study, statistical analysis, interpretation of data, critical revision.

${ }^{\vee} \mathrm{MD}$, Holy House of Mercy of Fortaleza, Professional Master's Degree Program in Minimally Invasive Technology and Simulation in Health, UNICHRISTUS, Fortaleza-CE, Brazil. Conception and design of the study, interpretation and analysis of data, critical revision, final approval.

\section{Abstract}

Purpose: To discuss the use of models of hepatic retraction by laparoscopy, to present a new Hepatic Retractor (HR) and to evaluate its practicality, efficacy and safety in Esophageal Hiatus Exposure (EHE).

Methods: Experimental cross- sectional study with a quantitative character. It was carried out in the Laboratory of Health Training of Christus University Center. The sample consisted of 12 livers of adult pigs weighing between 30 and $45 \mathrm{~kg}$. A circular-shaped HR, $5 \mathrm{~cm}$ diameter and deformable materials was developed with a polypropylene cloth, metallic guide wire, epidural needle plastic guide and nylon string. The practicality of HR management was measured by the time required to use the instrument, efficacy by exposure to the operative field and safety by macroscopic assessment of liver damage.

Results: The average time to complete the procedure was 3.24 minutes and reached less than 2 minutes after 12 repetitions. In eight experiments the maximum degree of EHE was obtained. No macroscopic lesions were observed.

Conclusion: The use of HR described can broaden the operative field, without causing macroscopic liver lesions and prolonging the surgical time.

Key words: Surgery. Laparoscopic. Liver. Swine. 


\section{Introduction}

Hepatic Retrator $(\mathrm{RH})$ is intended to increase Esophageal Hiatus Exposure (EHE) through the displacement of the Left Hepatic Lobe (LHL). Over the last few decades, numerous retractors and techniques have been developed to facilitate laparoscopic procedures in the upper abdomen ${ }^{1}$. As a way to compensate for the lack of instruments to move the LHL, some surgeons use tweezers, vacuum cleaners, wires, drains and probes ${ }^{2}$. It is known that the expansion of the operative field contributes to the surgical treatment of obesity ${ }^{3}$, gastric pathologies ${ }^{4}$ and gastro esophageal reflux disease ${ }^{5}$.

The principles of 3Rs (Reduction, Refinement and Replacement) are based on finding alternatives to reduce the number of animals in research ${ }^{6}$. The swine liver has an anatomical similarity with the organ of the human being. The segmental anatomy of the pig liver is well studied and has similarities with the human liver?. The elaboration of a new surgical instrument or its improvement is a challenging activity. The objective of this study is to discuss the use of HR models by laparoscopy, to present a new HR and to evaluate its practicality, efficacy and safety in the EHE.

\section{- Methods}

A quantitative cross-sectional study was carried out at the Christus University Center Health Training laboratory.

The sample consisted of 12 livers of male Landrace pigs. The organs weighed between 30 and $45 \mathrm{~kg}$ and were purchased in a meatpacker up to 6 hours before the experiment. The health surveillance standards have been respected.
The regulations of the National Council for the Control of Animal Experimentation (CONCEA) were observed to adopt an alternative method to the use of animals in research activities in Brazil'.

The pig liver (ex vivo model) was positioned within the cavity of the EndoSuture Training Box simulator. This abdominal cavity simulator is validated and used in teaching and research practices. It is capable of providing a suitable surgical field for the training of several surgical procedures ${ }^{9,10}$. All measures were performed by a single evaluator, avoiding any kind of unfairness. The experiments were performed one after the other, following the same pattern of procedures.

An HR prototype with circular shape and diameter of $5 \mathrm{~cm}$ was elaborated. Materials that were deformable and semirigid were searched for. After being deformed by some external force, the material should regain its original shape. After a technical drawing the author himself constructed an $H R$ with the materials available in the surgical arsenal (Figure 1). For the high memory rigid rod forming the perimeter of the HR, a metallic guide wire was used that composes the central venous access of the catheterization material. A polypropylene mesh commonly used in hernia repair was cut in a circular format to compose the central disk of the HR. A rigid central rod was made with the plastic guide that accompanies the needle used for epidural anesthesia. The 5.0 nylon thread had as a function to fix the materials to the polypropylene fabric. The estimated final cost for building HR was around \$45. An Invention Patent was filed with the National Institute of Industrial Property (INPI) with the following patent registration BR 102016028346-9. 


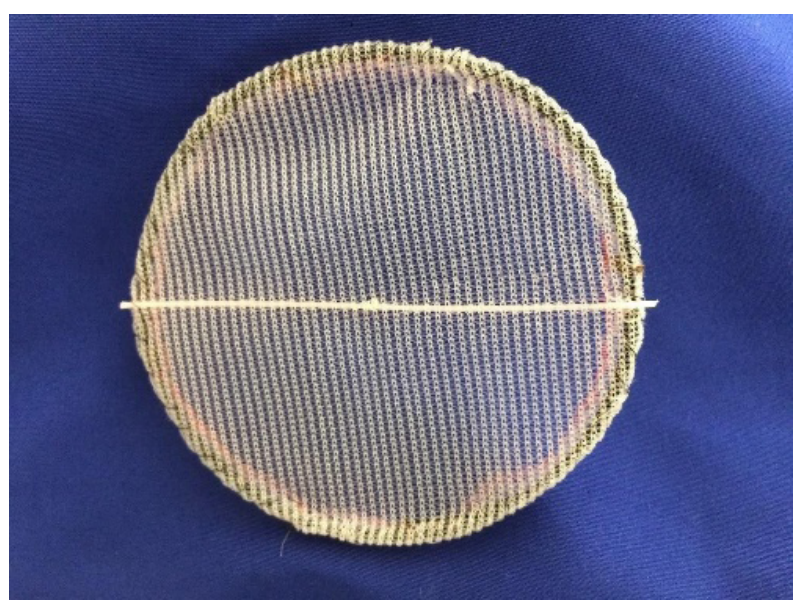

Figure 1 - HR prototype.

\section{Variables analyzed}

The practicality of HR management was measured by time. The time to enter the simulator (HR positioning at the entrance of the $10 \mathrm{~mm}$ trocarte coupled to the simulator) until the maximum static retraction of the liver for 10 seconds (T1) and the time between the end of the period of maximum static retraction of the liver to withdrawal of the simulator cavity (T2). The time was checked with the professional digital chronometer Vollo ${ }^{\circ} \mathrm{VI}-510$ C/10Memory.

To perform the HR efficacy experiment in providing surgical field, a tape measure and ruler behind the swine liver were fixed and the highest degree of liver retraction in centimeters was measured (Figure 2). The largest measure of retraction provided by $\mathrm{HR}$ was tabulated as degree 1 of exposure and the lowest measure of retraction as grade 3 . The intermediate measurement was tabulated as grade 2 of exposure. In case of not being able to see the tape measure due to insufficient retraction of the liver or it was not possible to maintain the maximum hepatic retraction for 10 seconds it was considered degree 4 of exposure. Measurements were performed at the time of greatest hepatic retraction.

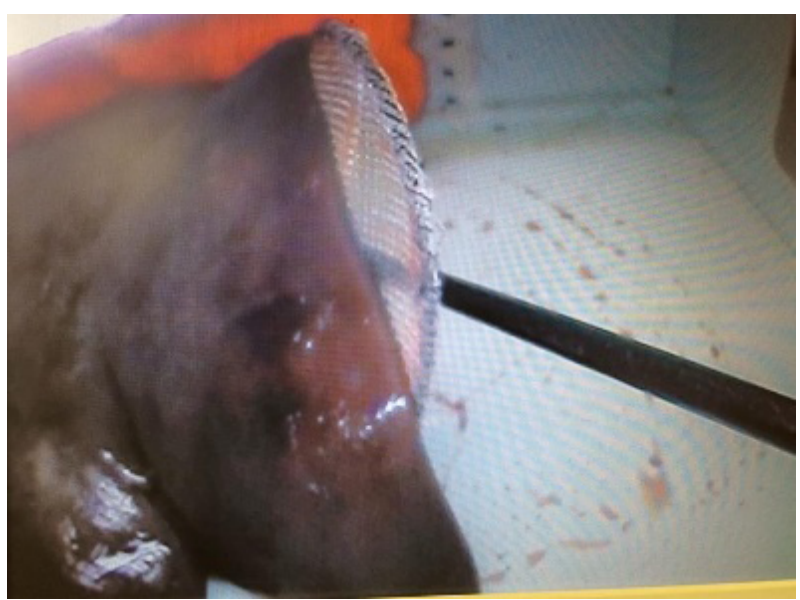

Figure 2 - Moment of greatest hepatic retraction.

Macroscopic liver lesion was assessed visually by identifying lesions on hepatic surfaces which suffered the HR direct action. Hepatic lesions were classified according to the graduation scale established by the American Association of Trauma Surgery ${ }^{11}$. The presence of lacerations or bruises (grade I to III) was evaluated. Vascular lesions (grade IV and V) and hepatic avulsion (grade $\mathrm{VI}$ ) do not apply to the experiment for the obvious reason of being an ex-vivo research model. Liver photographs (Nikon Coolpixp520 camera) were taken before and after the experiment for comparison and analysis. At the moment of greatest retraction, the force applied by the HR was measured on the surface of the liver. The measurement was performed by traction test using a digital dynamometer calibrated in Kilogram-force (kgf) with automatic lock function for stable data (Figure 3).

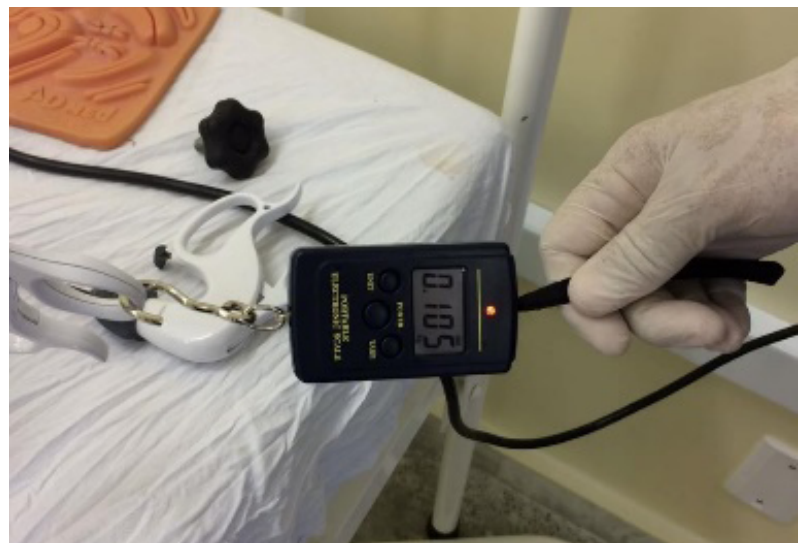

Figure 3 - Measurement of the force applied by HR. 


\section{Statistical analysis}

Categorical quantitative results were presented as percentages and counts. The collected data were tabulated and analyzed by SPSS software, v23, IBM, Inc.

\section{Results}

In Table 1, it was observed that the time to use the retractor was decreasing as it was being used and after 12 repetitions the evaluator took less than 2 minutes to do the HR positioning and withdrawal procedure. The average time to complete the procedure was 3.24 minutes.

Table 1 - Time for the use of HR.

\begin{tabular}{|c|c|c|c|}
\hline & (T1) & (T2) & Total Time \\
\hline Liver 1 & $3 \mathrm{~min} 48 \mathrm{seg}$ & $2 \min 14 \operatorname{seg}$ & $6 \mathrm{~min} 02 \mathrm{seg}$ \\
\hline Liver 2 & $2 \min 52 \mathrm{seg}$ & $1 \mathrm{~min} 23 \mathrm{seg}$ & $4 \min 15 \mathrm{seg}$ \\
\hline Liver 3 & $2 \mathrm{~min} 35 \mathrm{seg}$ & $1 \mathrm{~min} 12 \mathrm{seg}$ & $3 \min 47 \mathrm{seg}$ \\
\hline Liver 4 & $2 \mathrm{~min} 43 \mathrm{seg}$ & $1 \mathrm{~min} 10 \mathrm{seg}$ & $3 \min 53 \mathrm{seg}$ \\
\hline Liver 5 & $2 \mathrm{~min} 24 \mathrm{seg}$ & 48 seg & $3 \mathrm{~min} 02 \mathrm{seg}$ \\
\hline Liver 6 & $2 \min 26 s e g$ & $1 \mathrm{~min} 03 \mathrm{seg}$ & $3 \min 29 \mathrm{seg}$ \\
\hline Liver 7 & $1 \mathrm{~min} 56 \mathrm{seg}$ & 54 seg & 2 min50seg \\
\hline Liver 8 & $2 \mathrm{~min} 04 \mathrm{seg}$ & 47 seg & 2 min51seg \\
\hline Liver 9 & $1 \mathrm{~min} 58 \mathrm{seg}$ & 39seg & $2 \mathrm{~min} 37 \mathrm{seg}$ \\
\hline Liver 10 & $1 \mathrm{~min} 28 \mathrm{seg}$ & 49 seg & $2 \min 17 s e g$ \\
\hline Liver 11 & $1 \mathrm{~min} 18 \mathrm{seg}$ & $42 \mathrm{seg}$ & $2 \min 08 \min$ \\
\hline Liver 12 & $1 \mathrm{~min} 14 \mathrm{seg}$ & 36 seg & $1 \mathrm{~min} 50 \mathrm{seg}$ \\
\hline
\end{tabular}

Table 2 shows the maximum retraction of the left hepatic lobe and the EHE grade. It was found that at the beginning of the experiment it was possible to reach maximal liver retraction and the highest EHE. In eight experiments the maximum EHE degree was obtained.
Table 2 - Expansion of the operative field with HR.

\begin{tabular}{lcc}
\hline Experiments & $\begin{array}{c}\text { Maximum } \\
\text { Retraction }\end{array}$ & $\begin{array}{c}\text { Exposition } \\
\text { grade }\end{array}$ \\
\hline 1 & $10 \mathrm{~cm}$ & 3 \\
2 & $13 \mathrm{~cm}$ & 2 \\
3 & $13 \mathrm{~cm}$ & 2 \\
4 & $15 \mathrm{~cm}$ & 1 \\
5 & $15 \mathrm{~cm}$ & 1 \\
6 & $15 \mathrm{~cm}$ & 1 \\
7 & $13 \mathrm{~cm}$ & 2 \\
8 & $15 \mathrm{~cm}$ & 1 \\
9 & $15 \mathrm{~cm}$ & 1 \\
10 & $15 \mathrm{~cm}$ & 1 \\
11 & $15 \mathrm{~cm}$ & 1 \\
12 & $15 \mathrm{~cm}$ & 1 \\
\hline
\end{tabular}

No macroscopic lesions were observed in any of the 12 livers used in the experiments. Table 3 shows the force applied to the liver at the time of greatest retraction. There was a slight variation in the force used that was not able to cause bruising or lacerations in any of the scenarios.

Table 3 - Strength applied to the liver by HR.

\begin{tabular}{lll} 
& Kgf & N \\
\hline Liver 1 & 0.105 & 1.029 \\
Liver 2 & 0.110 & 1.078 \\
Liver 3 & 0.108 & 1.059 \\
Liver 4 & 0.121 & 1.186 \\
Liver 5 & 0.113 & 1.108 \\
Liver 6 & 0.103 & 1.010 \\
Liver 7 & 0.115 & 1.127 \\
Liver 8 & 0.118 & 1.157 \\
Liver 9 & 0.134 & 1.314 \\
Liver 10 & 0.125 & 1.225 \\
Liver 11 & 0.116 & 1.137 \\
Liver 12 & 0.112 & 1.098 \\
\hline
\end{tabular}

Kgf - Kilogram-force; N - Newton 


\section{- Discussion}

$H R$ is an important aspect in laparoscopic procedures of the upper abdomen. Surgeons have created several methods for HR because of limitations related to the absence of commercially available equipment. A review study analyzed the use of various hepatic retractors in the EHE and the time required for the EHE to be displaced through the analysis of surgical videos. Nasogastric tube (NG), hepatic suspension by puncture and drainage, $3 \mathrm{~mm}$ laparoscopic forceps, umbilical tape (sling method) and suture of the diaphragmatic pillar (crural suture) were used to mobilize the liver. The use of $3 \mathrm{~mm}$ laparoscopic forceps achieved the best EIE grade, followed by umbilical tape and NG suspension. The use of $3 \mathrm{~mm}$ laparoscopic forceps required less time to remove the liver (average of 2.8 minutes), followed by diaphragmatic pillar suture (average of 5.14 minutes) and NG suspension (average of 7 minutes). The average time to create liver retraction ranged from 2.8 to 8.6 minutes. The most used methods were: NG suspension ( 36 cases), umbilical tape ( 22 cases) and hepatic suspension by puncture and drain use (22 cases). It is not possible to compare these methods with what was used in ex vivo pig liver ${ }^{2}$.

A review study evaluated 10 instruments or techniques used for HR. Devices included were Nathanson liver retractor, liver suspension tape, V-List technique, a silicone disc with or without a snake retractor, Endoloop, Endograb, a magnetic retractor, the VaroLift, a laparoscope support and a retraction sponge. None of the instruments reported was associated with increased morbidity and conversion rates for open surgery. All articles reported that the instruments tested may save the use of the assistant during the procedure. All instruments were considered easy to use. It was not possible to determine the impact on the time of the surgical procedure due to heterogeneity of procedures and reduced sample. The authors reported good to excellent field of vision ${ }^{1}$. One study compared three different HR methods by laparoscopy during Roux-en-Y gastric bypass surgery. Sixty patients were randomly divided into groups. He evaluated Nathanson's HR and V-LIST (V-LIST) methods using penrose drain and tape suspension technique using the Jackson-Pratt drain. Hepatic dysfunction related to Nathanson's HR was observed, but there was no evidence of hepatic impairment. Postoperative pain was lower in the group that used hepatic suspension with Jackson-Pratt drain. Hepatic suspension techniques are easy to learn and do not need an extra incision for HR placement ${ }^{3}$.

It is possible to eliminate the need for a trocarte for the use of HR by using a suture in the upper portion of the right pillar with subsequent exteriorization of the two ends of the strand by a percutaneous device. The traction of the wire well positioned in the LHL is capable of suspending it and widening the operative field ${ }^{12}$. Another technique designed to suspend the LHL nontraumatically, uses a Penrose drain $8 \mathrm{~cm}$ long and $1 \mathrm{~cm}$ wide. Two sutures with silk strands were performed at both ends of the penrose prior to insertion of the drain into the abdominal cavity. After opening the triangular ligament, the drain is positioned under the left lateral segment of the liver and the silk thread is passed through the opening created by the section of the triangular ligament. The silk thread of approximately $10 \mathrm{~cm}$ at each end of the penrose is exteriorized from the abdominal cavity by improvisation of a device used for venous access puncture. After traction and fixation in the abdominal wall of the two ends of the wire a larger EHE is possible ${ }^{5}$.

One alternative that has proven to be effective and safe is to replace penrose with surgical gauze to suspend LHL. In this technique 
the yarn is exteriorized from the abdominal cavity through the use of straight needles at the ends of the gauze ${ }^{4}$. Moura-Júnior et al. ${ }^{13}$, used a zero-lined silk thread in $7 \mathrm{~cm}$ of nelaton probe to protect the hepatic parenchyma during $\mathrm{LHL}$ displacement. The wire had one end anchored to the right diaphragmatic pillar and the other to the portal to the left of the surgeon. The goal was to improve the EHE during 48 laparoscopic procedures of the upper abdomen. Placement of the flexible liver retractor did not increase operative time, was easy to handle, and may improve EHE during single port and robotic surgery.

A device for internal retraction of the liver was used in fourteen surgical procedures, through laparoscopic access, of the upper abdomen. The HR was formed by a disposable telescopic rod with anchoring jaws at each end. The retractor was introduced into the peritoneal cavity through a $5 \mathrm{~mm}$ trocarte and needed a proper tool to attach the left end previously to the diaphragmatic origin of the right pillar. The right extremity was medial to the falciform ligament and anchored to the peritoneum located below the left border of the liver. After fixation of the retractor, the fixation tool was removed and the trocarte made available for the use of other surgical clamps. Thus, it eliminated the need for an incision for the retractor and freed one of the surgeons' hands. The retractor was easy to use and allowed adequate exposure of the operative field in all procedures. There were no intra-operative or post-operative complications (intra-abdominal bleeding or diaphragm perforation) related to the device. The position time of the retractor improved with the experiment and reached approximately 1 minute ${ }^{14}$.

Shibao et al. ${ }^{15}$ used a leaf-shaped retractor and made with a rubber membrane and flexible memory structure as HR during laparoscopic surgeries of the upper abdomen. A snake retractor is needed to aid in liver retraction. An elastic band attached to the skin was used for the external fixation of the snake retractor and release of the auxiliary surgeon's hand. The entire procedure lasts less than 3 minutes and provides a better surgical field.

Transient elevation of hepatic enzymes has been described in the immediate postoperative period of surgeries that use some type of HR. This laboratory change is not usually related to clinical repercussions ${ }^{16}$. However, inadequate manipulation of an HR can lead to liver damage and, consequently, increase the surgery morbidity. Avoid applying excessive force to the liver and adjust the HR during long surgeries ${ }^{17}$. There are reports of more serious cases, such as hepatic lobe necrosis related to the use of $H R^{18}$. The described HR format allows a reduction of the force applied to the liver and, consequently, protection against liver damage. The greater the force required to manipulate $H R$, the less convenience for the surgeon and the greater possibility of loss of the surgical field. It was not possible to evaluate changes in liver enzymes because it is an ex vivo organ.

Although some liver elevation methods have been reported, obese patients and patients with hepatomegaly may not have good operative field exposure. The presented retractor appears as an effective alternative in the enlargement of the operative field by displacement of the $\mathrm{LHL}$, without prolonging the surgical time extensively. Due to the simplicity of the prototype construction and the wide availability of the materials needed for its manufacture, HR can be used in the surgical materials market as a lower cost alternative. Some disadvantages of the HR assessed are the need for an additional incision and occupation of one of the assisting surgeon's hands. The improvement of the HR and the manipulation technique of it can contribute to the resolution of these negative points. Studies in humans need to be performed to refine and test the described HR. 


\section{Conclusion}

The use of the described HR can increase the operative field, without causing macroscopic hepatic lesions and prolong the surgical time. Further studies are needed to validate and perfect this new surgical instrument.

\section{References}

1. Vargas-Palacios A, Hulme C, Veale $T$, Downey CL. Systematic Review of Retraction Devices for Laparoscopic Surgery. Surg Innov. 2015 Feb;23(1):90-101. doi: 10.1177/1553350615587991.

2. Palanivelu P, Patil KP, Parthasarathi $R$, Viswambharan JK, Senthilnathan $P$, Palanivelu C. Review of various liver retraction techniques in single incision laparoscopic surgery for the exposure of hiatus. J Min Access Surg. 2015 JulSep;11(3):198-202. doi: 10.4103/09729941.140202.

3. Goel R, Shabbir A, Tai CM, Eng A, Lin HY, Lee $\mathrm{SL}$, Huang CK. Randomized controlled trial comparing three methods of liver retraction in laparoscopic Roux-en-Y gastric bypass. Surg Endosc. 2013 Feb;27(2):679-84. doi: 10.1007/s00464-012-2438-6.

4. Woo Y, Hyung WJ, Kim HI, Obama K, Son T, Noh SH. Minimizing hepatic trauma with a novel liver retraction method: a simple liver suspension using gauze suture. Surg Endosc. 2011 Dec;25(12):3939-45. doi: 10.1007/ s00464-011-1788-9.

5. Hamzaoglu I, Karahasanoglu T, Aytac E, Karatas A, Baca B. Transumbilical totally laparoscopic single-port nissen fundoplication: a new method of liver retraction: the Istanbul technique. J Gastrointest Surg. 2010 Jun;14(6):1035-9. doi: 10.1007/s11605-010-1183-1.

6. Cazarin KC, Corrêa CL, Zambrone FA. Redução, refinamento e substituição do uso de animais em estudos toxicológicos: uma abordagem atual. Rev Bras Ciênc Farm. 2004 Jul;40(3):289-98. doi: 10.1590/S151693322004000300004.

7. Court FG, Wemyss-Holden SA, Morrison $\mathrm{CP}$, Teaque BD, Laws PE, Kew J, Dennison
AR, Maddem GJ. Segmental nature of the porcine liver and its potential as a model for experimental partial hepatectomy. $\mathrm{Br} \mathrm{J}$ Surg. 2003 Apr;90(4):440-4. doi: 10.1002/ bjs.4053.

8. Guimarães MV, Freire JE, Menezes LM. Utilização de animais em pesquisas: breve revisão da legislação no Brasil. Rev Bioét. 2016 May;24(2): 217-24. doi: 10.1590/198380422016242121.

9. Barreira MA, Siveira DG, Rocha HA, MouraJunior LG, Mesquita CJ, Borges GC. Model for simulated training of laparoscopic gastroenterostomy. Acta Cir Bras. 2017 Jan:32(1):81-9. doi: 10.1590/s0102865020170110.

10. Ferreira Filho F, Moura Júnior LG, Rocha HA, Rocha SG, Ferreira LF, Ferreira AF. Abdominal cavity simulator for skill progression in videolaparoscopic sutures in Brazil. Acta Cir Bras. 2018 Jan;33(1):75-85. doi: 10.1590/ s0102-865020180010000008.

11.Coccolini F, Catena F, Moore EE, Ivatury R, Biffl W, Peitzman A, Coimbra R, Rizoli S, Kluger Y, Abu-Zidan FM, Ceresoli M, Montori G, Sarteli M, Weber D, Naidoo N, Moore FA, Zanini N, Ansaloni L. WSES classification and guidelines for liver trauma. World J Emerg Surg. 2016 Oct 10;11:50. doi: 10.1186/ s13017-016-0105-2.

12.De la Torre RA, Satgunam S, Morales MP, Dwyer CL, Scott JS. Transumbilical singleport laparoscopic adjustable gastric band placement with liver suture retractor. Obes Surg. 2009 Dec;19(12):1707-10. doi: 10.1007/s11695-009-9896-5.

13.Moura-Júnior LG, Castro-Filho HF, Machado $\mathrm{FH}$, Babadopulos RF, Feijó FC, Fernandes SD. Minimização de portais com miniportes e afastador flexível de fígado: alternativa ergonômica e estética ao single port em bypass gástrico laparoscópico. Arq Bras Cir Dig. 2014 Jul;27(Suppl 1):77-9. doi:10.1590/ s0102-6720201400s100019.

14.Elazary R, Kedar A, Shussman N, Abu-Gazala M, Khalaileh A, Faroja M, Rivkind AL, Mintz Y. A novel totally internal laparoscopic liver retractor. Surg Laparosc Endosc Percutan Tech. 2013 Dec;23(6):e222-4. doi: 10.1097/ SLE.0b013e31828e3fc5.

15.Shibao K, Higure A, Yamaquchi K. Disk suspension method: a novel and safe technique for the retraction of the liver 
during laparoscopic surgery (with video). Surg Endosc. 2011 Aug;25(8):2733-7. doi: 10.1007/s00464-011-1614-4.

16.Morris-Stiff G, Jones R, Mitchell S, Barton $\mathrm{K}$, Hassn A. Retraction transaminitis:an inevitable but benign complication of laparoscopic fundoplication. World J Surg. 2008 Dec;32(12):2650-4. doi: 10.1007/ s00268-008-9744-0.
17.Nozaki T, Kato T, Komiya A, Fuse H. Retractionrelated acute liver failure after urological laparoscopic surgery. Curr Urol. 2014 Oct;7(4):199-203. doi: 10.1159/000365676. 18. Tamhankar AP, Kelty CJ, Jacob G. Retraction-related liver lobe necrosis after laparoscopic gastric surgery. JSLS. 2011 JanMar;15(1):117-21. doi: 10.4293/108680811 X13022985131651.

\section{Correspondence:}

Delano Gurgel Silveira

Avenida Beira Mar,3960/2304

60165121 Fortaleza - CE Brasil

Tel.: (55 85)98822-9299

delanogs@gmail.com

Received: July 22, 2018

Review: Sept 19, 2018

Accepted: Oct 20, 2018
Conflict of interest: none

Financial source: none

${ }^{1}$ Research performed at Training Laboratory in Health, Centro Universitário Christus (UNICHRISTUS), Fortaleza-CE, Brazil. Part of Master degree thesis, Postgraduate Program in Minimally Invasive Technology and Health Simulation. Tutor: Gleydson Cesar de Oliveira Borges. 